\title{
OS MECANISMOS DO TRIBUNAL DE JUSTIÇA DA UNIÃO EUROPEIA E A PROTEÇÃO DOS DIREITOS FUNDAMENTAIS
}

\author{
Eduardo Biacchi Gomes 1 \\ Luís Alexandre Carta Winter ${ }^{2}$
}

\section{RESUMO}

O presente artigo abordará mais a existência e a necessidade de efetivos mecanismos de controles jurisdicionais, com o intuito de observar a proteção dos direitos fundamentais dentro da União Europeia. Bem como, a divisão de competências entre as instituições do bloco econômico e as jurisdições nacionais, e a importante atuação do Tribunal de Justiça da União Europeia. No tocante aos mecanismos de proteção aos direitos fundamentais abrangeremos um constante diálogo entre a jurisdição supranacional e as jurisdições nacionais, com o objetivo de garantir a uniformidade na interpretação e na aplicação do Direito da União Europeia. A metodologia utilizada para o desenvolvimento foi através de uma pesquisa bibliográfica. O que se verifica nesse estudo é um maior respeito aos direitos dos cidadãos da União Europeia, no sentido de se buscar uma autoafirmação no próprio conceito de cidadania comunitária e a possibilidade de se buscar a tutela dos direitos ali dispostos, tanto dentro das jurisdições nacionais, como na supranacional.

PALAVRAS-CHAVE: Mecanismos; União Europeia; Direitos Fundamentais.

\section{INTRODUÇÃO}

A União Europeia, inquestionavelmente, traduz-se no melhor exemplo de integração concretizado ao longo dos últimos cinquenta anos. Concretamente, desde a

\footnotetext{
${ }^{1}$ Pós Doutorado, Doutor em Direito pela Universidade Federal do Paraná, Professor do Programa de Mestrado em Direito da UniBrasil e Vice coordenador do mesmo Programa. Professor Titular de Direito Internacional da PUCPR e Professor colaborador do PPGD em Direito da PUCPR.

${ }^{2}$ Doutor em Direito pelo Prolan (USP), Professor Titular de Direito Internacioal da PUCPR e Professor do PPGD da PUCPR. Professor do UniCuritiba
} 
criação da Comunidade Econômica Europeia, com o Tratado de Roma do ano de 1957, os seus países fundadores (Alemanha, França, Itália, Bélgica, Holanda e Luxemburgo), iniciaram a construção de um modelo de integração pautado não somente em valores do mercado, mas igualmente com o intuito de observar outras políticas: como os direitos fundamentais e sociais.

No estágio atual a União Europeia compreende um total de 28 (vinte e oito) Estados-Membros em um modelo de integração que compreende a livre circulação de bens, pessoas, serviços, capitais, além de uma moeda única que é o Euro.

Vale destacar que o Tratado Reformador de Lisboa $^{3}$, do ano de 2009 teve como um de seus principais objetivos consolidar o processo integracionista europeu, de forma a inserir a Carta Europeia de Direitos Fundamentais dentro do acervo jurídico da União Europeia, e que se traduz em "um conjunto de direitos pessoais, cívicos, políticos, econômicos e sociais dos cidadãos comunitários” ${ }^{4} \mathrm{e}$, para tanto, aplica-se dentro das instituições do bloco como em relação aos Estados-Membros, nas matérias de competências exclusivas ou concorrentes.

Assim, o Tratado de Lisboa possibilita outro âmbito de aplicação e de proteção dos direitos fundamentais, além das esferas nacionais e do Sistema Europeu de Proteção aos Direitos Humanos e que diz respeito ao Direito da União Europeia. Aqui, aplicar-se-á o disposto na Carta Europeia de Direitos Fundamentais, sempre que a questão versar sobre alguma matéria de competência legislativa das Instituições da União Europeia.

Cumpre destacar que o ingresso de Portugal, dentro da União Europeia (1986) e da República Checa (2004), ocorreu em momentos históricos distintos. No ano de 1986 a atual União Europeia passava por um momento de consolidação em que existiam recursos para

\footnotetext{
${ }^{3}$ Assinado em 13.12.2007, como é mais conhecido o Tratado Reformulador dos Tratados Europeus, assinado pelos 27 Estados-Membros da União Europeia, que modificou o Tratado da União Europeia e o Tratado Constitutivo da Comunidade Europeia. Previu-se que os instrumentos de ratificação deveriam ser depositados até 01.01.2009, data oficial marcada para sua entrada em vigor na ordem jurídica comunitária. José Cretella Neto. Curso de Direito Internacional Econômico, ed.Saraiva: SP, 2012, p.557.

${ }^{4}$ Disponível em:

<http://europa.eu/legislation_summaries/justice_freedom_security/combating_discrimination/l335 01_pt.htm>. Acesso em: 04 maio 2014.
} 
possibilitar o crescimento e o desenvolvimento dos países que recém- ingressavam no bloco, como foi o caso de Portugal.

Em 2004, ano em que houve o grande alargamento do bloco, que passou de 15 (quinze) para 25 (vinte e cinco) países, oito (8) deles - incluindo-se a República Checa eram oriundas do Leste europeu e, consequentemente, foram obrigadas a adaptar as suas economias aos padrões de uma economia de Mercado, o que gerou uma integração em dois níveis: a dois países mais antigos e que possuíam níveis equilibrados de desenvolvimentos e os demais países, que progressivamente foram se adaptando ao mercado comum e não receberam os mesmos recursos de investimentos destinados aos países que ingressaram no bloco na década de 1980: como a Grécia, Espanha ou Portugal.

Assim, tendo em vista a nova realidade econômica e mundial, que é a formação dos blocos econômicos, o presente artigo tem por objetivo examinar, sob a ótica do Direito da União Europeia e do Direito Internacional dos Direitos Humanos, a atuação do Tribunal de Justiça da União Europeia, com sede em Luxemburgo, como órgão de caráter supranacional na aplicação da Carta Europeia de Direitos Fundamentais. Para tanto, partese de um marco teórico sobre a aplicação dos direitos fundamentais dentro da União Europeia, a sua relação com a Convenção Europeia de Direitos Humanos e, finalmente, busca-se relacionar os aspectos teóricos com estudos de caso.

\section{ORDENAMENTO JURÍDICO SUPRANACIONAL E DIREITOS FUNDAMENTAIS}

A construção e a consolidação de um mercado comum em que estão integrados 28 (vinte e oito) Estados de economias díspares, inquestionavelmente pressupõe a necessidade da observância de políticas comuns.

Com o advento do Tratado de Maastrich, 1992, foi criada a União Europeia, que ao lado da Comunidade Europeia, objetivou-se o aprofundamento do processo integracionista, 
além da própria cidadania europeia ${ }^{5}$, de forma a inserir o nacional dos Estados-Membros dentro da integração.

Vale destacar que a Carta Europeia de Direitos Fundamentais somente é aplicável para as hipóteses relacionadas com as competências da União Europeia, como por exemplo, a não transposição de uma diretiva. Assim caberá ao particular, quando for o caso, invocar a proteção de seus direitos junto aos tribunais nacionais e, caso a violação persista, poderá ser acionada a Comissão que, por sua vez, demandará contra o Estado mediante a Ação por Incumprimento ${ }^{6}$. Assim, o "fator de conexão dependerá do caso em concreto" e, mesmo assim poderá ser apresentada uma petição perante a Corte Europeia de Direitos Humanos, desde que fique evidenciada a violação a Convenção Europeia de Direitos Humanos e desde que esgotados os recursos internos locais.

Objetivamente, o Relatório sobre a aplicação da Carta Europeia de Direitos Fundamentais, elaborado pela Comissão Europeia, aponta que entre os anos de 2009 até 2011, aumentou o número das decisões dentro do Tribunal de Justiça da União Europeia e que fazem referência a Carta Europeia. No ano de 2009, constatou-se um total de cinco decisões, e no ano de 2011 o número de casos analisados foi de 42 . Dos 42 casos, 24\% (vinte e quatro por cento) referiram-se a questões sobre liberdade, e 44\% (quarenta e quatro por cento) sobre justiça.

Tendo em vista as peculiaridades do Direito da União Europeia, que é dotado - ao mesmo tempo de independência e autonomia frente o direito interno e o direito

\footnotetext{
${ }^{5}$ Conforme estabelecido no Tratado da União Europeia, a cidadania europeia atribui aos nacionais dos Estados-Membros do bloco o direito de votar e de ser votado ao Parlamento europeu, assim como o direito de votarem e de serem votados para as eleições municipais dos Estados em que residem, direito de circularem e de residirem livremente dentro dos Estados-Membros do bloco, direito de apresentação de queixa junto ao Provedor de Justiça europeu e o direito de invocar a protecão diplomática de um Estado, diferente do seu, desde que não exista a representação de seu Estado de origem. Disponível em: <http://europa.eu/legislation_summaries/institutional_affairs/treaties/treaties_maastricht_pt.htm>. Acesso em: 04 maio 2014.

${ }^{6}$ Comissão Europeia. Relatório de 2011 sobre a aplicação da Carta Europeia de Direitos Fundamentais. Luxemburgo: Serviço de Publicações da União Europeia, 2012. p. 24-25.

Disponível em: 〈http://www.igfse.pt/upload/docs/2013/Reldireitosfundamentais2011.pdf>. Acesso em: 04 maio 2014.
} 
internacional - em virtude da aplicação de seus princípios ${ }^{7}$, torna-se imprescindível a correta e constante atuação por parte dos tribunais nacionais que, ao mesmo tempo, são juízes comunitários, porque interpretam e aplicam as normativas supranacionais ${ }^{8}$.

Com o intuito de se buscar a correta interpretação e aplicação do Direito da União Europeia, imprescindível à existência de mecanismos processuais que permitam a cooperação judiciária entre a instância supranacional e as dos Estados-Membros da União Europeia. O mecanismo existente dentro da União Europeia e previsto no Tratado Reformador de Lisboa é o chamado Reenvio Prejudicial ${ }^{9}$, de forma a dar subsídios ao juiz nacional, no sentido de saber como aplicar a norma supranacional ${ }^{10}$.

O Acórdão proferido pelo Tribunal de Justiça da União Europeia possui natureza jurídica vinculante, ou seja, ainda que a competência para dirimir a questão seja do juiz nacional, a sua decisão ficará vinculada aos termos da interpretação dada pelo Tribunal supranacional. Vale destacar, ademais, que a competência para suscitar o reenvio é do próprio juiz nacional. Nas instâncias nacionais em que a sentença ainda é passível de recurso, o reenvio é facultativo e nas extraordinárias, isto é, em que não é mais possível a

\footnotetext{
${ }^{7}$ Aplicabilidade direta, através da qual a normativa da União Europeia, a partir do momento que é publicada no Diário Oficial da União Europeia, já passa a gerar efeitos jurídicos; Primado, através do qual - nas matérias de competências concorrentes e se houver conflito entre a norma supranacional e a nacional, prevalecerá a primeira; Uniformidade na Interpretação e na Aplicação do Direito da União Europeia, através do qual as normativas supranacionais deverão ser interpretadas e aplicadas de maneira uniforme pelos juízes nacionais. ${ }^{8}$ Sobre o assunto ver artigo de Francisco Balaguer Callejón - "As relações entre o Tribunal de Justiça da União Europeia e os Tribunais Constitucionais dos Estados-Membros", publicado na Revista Brasileira de Direitos Fundamentais e Justiça n.13, PUCRS, out/dez 2010.

O Tribunal de Justiça da União Europeia é competente para decidir, a título prejudicial:

a) Sobre a interpretação dos Tratados;

b) Sobre a validade e a interpretação dos actos adoptados pelas instituições, órgãos ou organismos da União. Sempre que uma questão desta natureza seja suscitada perante qualquer órgão jurisdicional de um dos Estados-Membros, esse órgão pode, se considerar que uma decisão sobre essa questão é necessária ao julgamento da causa, pedir ao Tribunal que sobre ela se pronuncie.

Sempre que uma questão desta natureza seja suscitada em processo pendente perante um órgão jurisdicional nacional cujas decisões não sejam susceptíveis de recurso judicial previsto no direito interno, esse órgão é obrigado a submeter à questão ao Tribunal.

Se uma questão desta natureza for suscitada em processo pendente perante um órgão jurisdicional nacional relativamente a uma pessoa que se encontre detida, o Tribunal pronunciar-se-á com a maior brevidade possível.

${ }^{10}$ GOMES,Eduardo Biacchi. Manual de Direito da Integração Regional, 2a .ed., Juruá:2014. P.89.
} 
interposição de recurso, o reenvio é obrigatório.

A utilização do reenvio prejudicial, portanto, tem contribuído ao longo do tempo para a consolidação do Direito da União Europeia, de forma a possibilitar a interpretação e aplicação uniforme do direito supranacional, com o objetivo de se criar uma verdadeira jurisprudência do Direito da União Europeia e que deve ser observada pelos EstadosMembros do bloco.

Cumpre observar que as instituições da União Europeia somente poderão atuar naquelas matérias em que houve - expressamente - a delegação de competências legislativas por parte dos Estados, as quais se dividem em: exclusivas, concorrentes e privativas dos Estados.

Dentro das matérias de competência exclusiva da União Europeia ${ }^{11}$ os Estados não poderão mais legislar, vez que renunciaram a prerrogativa legislativa em favor das instituições supranacionais (Parlamento, Comissão e Conselho). Aqui, caberá ao EstadoMembro da União Europeia, o dever de aplicar e de observar as referidas normativas, assim como não frustrar o seu cumprimento.

Dentro das matérias de competência concorrente ${ }^{12}$, tanto os Estados-Membros da

\footnotetext{
${ }^{11}$ Artigo $3^{\circ}$ do Tratado sobre o Funcionamento da União Europeia.

1. A União dispõe de competência exclusiva nos seguintes domínios:

a) União aduaneira;

b) Estabelecimento das regras de concorrência necessárias ao funcionamento do mercado interno;

c) Política monetária para os Estados-Membros cuja moeda seja o euro;

d) Conservação dos recursos biológicos do mar, no âmbito da política comum das pescas;

e) Política comercial comum.

12 Artigo $4^{\circ}$ do Tratado sobre o Funcionamento da União Europeia.

1. A União dispõe de competência partilhada com os Estados-Membros quando os Tratados lhe atribuam competência em domínios não contemplados nos artigos $3^{\circ}$ e $6^{\circ}$.

2. As competências partilhadas entre a União e os Estados-Membros aplicam-se aos principais domínios a seguir enunciados:

a) Mercado interno;

b) Política social, no que se refere aos aspectos definidos no presente Tratado;

c) Coesão econômica, social e territorial;

d) Agricultura e pescas, com excepção da conservação dos recursos biológicos do mar;

e) Ambiente;

f) Defesa dos consumidores;

g) Transportes;

h) Redes transeuropeias;

i) Energia;

j) Espaço de liberdade, segurança e justiça;
} 
União Europeia como as suas instituições possuem a competência para legislar. Entretanto, tendo em vista a aplicação do princípio do primado da norma da União Europeia frente a nacional esta nunca poderá contrariar a primeira.

Oportuno lembrar, ademais, as competências de apoio da União Europeia, aplicável àquelas matérias de competência privativa dos Estados. No caso específico, caberá à União Europeia atuar subsidiariamente, com o intuito de complementar as ações adotadas pelos Estados ${ }^{13}$.

O Tratado Reformador de Lisboa, que atualmente regulamenta o Direito da União Europeia, aperfeiçoou, portanto o mecanismo de efetividade das normas supranacionais, ao delimitar - como visto acima - as matérias de competência exclusiva dos órgãos supranacionais - reconhecendo, expressamente, que as normativas supranacionais são juridicamente vinculativas aos Estados. No que diz respeito às matérias de competência concorrente, o Tratado de Lisboa reconhece a primazia da norma supranacional frente às normas nacionais, sendo que os Estado podem legislar concorrentemente e na medida em que não ocorra a violação com a norma supranacional ${ }^{14}$.

k) Problemas comuns de segurança em matéria de saúde pública, no que se refere aos aspectos definidos no presente Tratado.

3. Nos domínios da investigação, do desenvolvimento tecnológico e do espaço, a União dispõe de competência para desenvolver acções, nomeadamente para definir e executar programas, sem que o exercício dessa competência possa impedir os Estados-Membros de exercerem a sua.

4. Nos domínios da cooperação para o desenvolvimento e da ajuda humanitária, a União dispõe de competência para desenvolver ações e uma política comum, sem que o exercício dessa competência possa impedir os Estados-Membros de exercerem a sua.

${ }^{13}$ Artigo $6^{\circ}$ do Tratado sobre o Funcionamento da União Europeia.

ARTIGO $6^{\circ}$

A União dispõe de competência para desenvolver ações destinadas a apoiar, coordenar ou completar a ação dos Estados-Membros.

São os seguintes os domínios dessas ações, na sua finalidade europeia:

a) Protecção e melhoria da saúde humana;

b) Indústria;

c) Cultura;

d) Turismo;

e) Educação, formação profissional, juventude e desporto;

f) Protecção civil;

g) Cooperação administrativa.

${ }^{14}$ É o contraponto europeu à máxima "a crueldade selvagem que imprimia na carne a marca territorial é substituída pelo terror que o aparelho de Estado faz reinar”, de François Châtelet e Évelyne Pisier-Kouchner, As Concepções Políticas do Século XX - História do Pensamento Político, Zahar:RJ,1983,p.690. 
Como forma de melhor ilustrar a matéria, importante destacar que os Regulamentos são - tipicamente - normativas supranacionais e que possuem o objetivo de uniformizar temas de grande interesse ao Direito da União Europeia e, como tal, possuem aplicabilidade direta e vinculam os seus destinatários (Estados, Instituições comunitárias e os particulares).

Também em relação às normativas supranacionais, vale destacar as diretivas que tem a finalidade de promover uma harmonização no Direito da União Europeia. A diretiva é entendida como uma lei-quadro, que estabelece normas gerais sobre uma determinada matéria e os Estados podem legislar concorrentemente e desde que a norma nacional não viole a supranacional. Por fim, os Estados possuem uma obrigação de resultado, quanto ao prazo para a transposição da diretiva em seus ordenamentos jurídicos. Diferentemente dos regulamentos, as diretivas vinculam os Estados e os particulares.".

Não há que se olvidar que a efetividade do direito derivado da União Europeia, somente é possível porque os ordenamentos constitucionais dos EstadosMembros asseguram dispositivos, de forma a possibilitar o relacionamento entre o Direito da União Europeia e os ordenamentos jurídicos nacionais.

Em verdade, são verdadeiras cláusulas de abertura e de diálogo ${ }^{15}$, que estão

\footnotetext{
${ }^{15}$ Neste sentido, vide o exemplo das Constituições de Portugal e da República Checa: CONSTITUIÇÃO DE PORTUGAL
}

Art. $7^{\circ}$ [Relações Internacionais]

1. Portugal rege-se nas relações internacionais pelos princípios da independência nacional, do respeito dos direitos do homem, dos direitos dos povos, da igualdade entre os Estados, da solução pacífica dos conflitos internacionais, da não ingerência nos assuntos internos dos outros Estados e da cooperação com todos os outros povos para a emancipação e o progresso da humanidade.

(...)

6. Portugal pode, em condições de reciprocidade, com respeito pelo princípio da subsidiariedade e tendo em vista a realização da coesão econômica e social, convencionar o exercício em comum dos poderes necessários à construção da União Europeia. CONSTITUIÇÃO DA REPÚBLICA CHECA

Art. 10a. Um acordo internacional poderá acarretar a transferência de determinados poderes de órgãos da República Checa à uma organização ou instituição internacional. É necessária a aprovação do Parlamento para que o acordo internacional estipulado na subseção 1 seja ratificado, a menos que uma lei constitucional requeira aprovação mediante referendo.

Considerando ser, originalmente, os Blocos Econômicos, um braço do Direito Internacional Econômico, Celso Duviver de Albuquerque Mello, Curso de Direito Internacional Público, ed. Renovar, 2001, p.1620, 
previstas nas Constituições dos Estados-Membros do bloco e que permitem uma assimilação entre o ordenamento jurídico supranacional e os ordenamentos jurídicos nacionais, fazendo com que as primeiras sejam aplicadas pelos poderes executivo, legislativo e judiciário de cada Estado, o que contribui para a uniformidade na aplicação e na interpretação do direito comunitário ${ }^{16}$.

\section{CARTA EUROPEIA DE DIREITOS FUNDAMENTAIS E A ATUAÇÃO DO TRIBUNAL DE JUSTIÇA DA UNIÃO EUROPEIA}

Para que o Direito da União Europeia possa ser efetivo, torna-se importante a existência de um eficaz mecanismo de solução de controvérsias e que, em última instância, deverá ter as competências para efetuar a fiscalização sobre a correta interpretação e aplicação das normas comunitárias dentro dos ordenamentos jurídicos dos Estados.

Dentro da União Europeia, dita função é exercida pelo Tribunal de Justiça da União Europeia, corte de natureza jurídica supranacional, sediada em Luxemburgo e que tem por competência efetuar o devido controle do direito supranacional ${ }^{17}$.

Vale destacar, ademais, que com o advento do Tratado Reformador de Lisboa, como visto na parte introdutória do presente artigo, a temática referente aos Direitos Fundamentais passou a ganhar uma maior dimensão, tendo em vista a inserção da Carta Europeia de Direitos Fundamentais dentro do acervo jurídico comunitário, o que faz com que se torne necessária a existência, cada vez maior, de uma conscientização por parte

sustenta que "Nas organizações internacionais econômicas procura-se o compromisso justo, sendo ele mais importante do que a aplicação rígida do Direito. Daí as negociações terem uma grande importância para a solução dos litígios".

${ }^{16}$ É verdade que isto é um desejo antigo europeu, vários foram os estadistas europeus que ambicionaram, de alguma forma, uma Europa Unida, mas é pela primeira vez que isto se faz pela força da Lei. Em modelos anteriores é interessante ver a obra de George Frost Kennan, O Declínio da Ordem Europeia de Bismarck, UNB:Brasília, 1985.

17 Referido controle é exercido através das ações previstas no Tratado de Lisboa, a saber: Reenvio Prejudicial (que garante a uniformidade na interpretação e na aplicação do direito comunitário); Ação por Incumprimento (que objetiva obrigar um Estado a que cumpra com a norma comunitária); Ação de Anulação (que tem por objetivo declarar nula uma norma comunitária) e Recurso por Omissão, que objetiva fazer com que uma instituição comunitária se pronuncie sobre uma questão de direito comunitário, quanto, por força do Tratado, esteja obrigada a assim proceder. 
dos cidadãos comunitários, sobre a sua existência e a necessidade de buscarem a tutela de seus direitos, tanto nas jurisdições nacionais, como perante o Tribunal de Justiça da União Europeia (sempre que a matéria for afeta aos temas do Mercado Comum).

Com o novo status conferido à Carta Europeia de Direitos Fundamentais, certo é que as legislações nacionais deverão se adequar aos seus preceitos e, neste sentido, tanto o Conselho, como o Parlamento e a Comissão da União Europeia, tem desempenhado importante papel no sentido de conscientizar os cidadãos comunitários sobre a sua importância e efetivação ${ }^{18}$.

Aliás, com a Carta Europeia de Direitos Fundamentais, tendo em vista a possibilidade de os nacionais dos Estados-Membros da União Europeia postularem os direitos ali elencados perante as jurisdições nacionais como junto ao Tribunal de Justiça da União Europeia, aperfeiçoa o próprio conceito de cidadania comunitária, de forma a questionar os valores seculares do Estado-nação em que a cidadania era, meramente, um pressuposto da nacionalidade.

Na dimensão ora proposta, o conceito de cidadania é alargado para dimensões regionais, em que o nacional de um dos Estados-Membros do bloco possui - ao mesmo tempo - a cidadania de seu Estado e a da União Europeia, que lhe garante prerrogativas, não somente em relação às quatro liberdades de mercado (livre circulação de bens, pessoas, serviços e capitais), mas igualmente a possibilidade de tutela em relação aos direitos fundamentais dentro da União Europeia ${ }^{19}$.

\footnotetext{
${ }^{18}$ Comissão Europeia. Relatório de 2011 sobre a aplicação da Carta Europeia de Direitos Fundamentais. Luxemburgo: Serviço de Publicações da União Europeia, 2012. p. 5.

Disponível em: 〈http://www.igfse.pt/upload/docs/2013/Reldireitosfundamentais2011.pdf>. Acesso em: 06 maio 2014.

${ }^{19}$ A título exemplificativo da nova dimensão do Direito da União Europeia cumpre asseverar que a própria Carta Europeia de Direitos Fundamentais assegura a integração com as pessoas com deficiência e, neste sentido, a União Europeia ratificou, em data de 22 de janeiro de 2011, a Convenção das Nações Unidas sobre os direitos das pessoas com deficiência, de forma a garantir que os direitos ali elencados sejam observados pela União Europeia, "nas suas medidas legislativas, bem como na formulação de políticas (dentro) de suas competências".

Comissão Europeia. Relatório de 2011 sobre a aplicação da Carta Europeia de Direitos Fundamentais. Luxemburgo: Serviço de Publicações da União Europeia, 2012. p. 63.
} 
Com o intuito de desenvolver a cidadania dentro da União Europeia, o relatório da Comissão Europeia sobre a aplicação da Carta Europeia de Direitos Fundamentais ${ }^{20}$, expressa que as Instituições da União Europeia têm realizado todos os esforços no sentido de buscar a promoção entre homens e mulheres, de forma a reduzir as desigualdades dentro de áreas estratégicas como: emprego, educação social, remunerações iguais para funções iguais etc.

Especificamente na área da solidariedade, que é uma das matérias elencadas dentro da Carta Europeia de Direitos Fundamentais, o Relatório da Comissão Europeia $^{21}$ aponta avanços nas políticas voltadas para a prestação de informações e consultas aos trabalhadores, especialmente em relação aos trabalhadores transnacionais, isto é: aqueles que se deslocam para outros Estados para exercerem as suas atividades, assim como a Comissão iniciou o procedimento voltado a aplicar as multas aos Estados que não internalizaram a referida diretiva sobre o tema ${ }^{22}$.

No mesmo sentido a Carta Europeia de Direitos Fundamentais reconhece o direito de greve e de negociação coletiva dos trabalhadores, muito embora - conforme esclareçe o Relatório da Comissão - não exista uma legislação comunitária específica sobre a matéria, ficando os Estados-Membros vinculados aos termos da Carta ${ }^{23}$.

Disponível em: <http://www.igfse.pt/upload/docs/2013/Reldireitosfundamentais2011.pdf〉. Acesso em: 06 maio 2014.

${ }^{20}$ Comissão Europeia. Relatório de 2011 sobre a aplicação da Carta Europeia de Direitos Fundamentais. Luxemburgo: Serviço de Publicações da União Europeia, 2012. p. 9 e ss.

Disponível em: 〈http://www.igfse.pt/upload/docs/2013/Reldireitosfundamentais2011.pdf>. Acesso em: 06 maio 2014.

${ }^{21}$ Comissão Europeia. Relatório de 2011 sobre a aplicação da Carta Europeia de Direitos Fundamentais. Luxemburgo: Serviço de Publicações da União Europeia, 2012. p. 63.

Disponível em: <http://www.igfse.pt/upload/docs/2013/Reldireitosfundamentais2011.pdf>. Acesso em: 06 maio 2014.

Comissão Europeia. Relatório de 2011 sobre a aplicação da Carta Europeia de Direitos Fundamentais. Luxemburgo: Serviço de Publicações da União Europeia, 2012. p. 67 e ss.

Disponível em: $<$ http://www.igfse.pt/upload/docs/2013/Reldireitosfundamentais2011.pdf >. Acesso em: 06 maio 2014.

${ }^{22}$ Vide nota de rodapé 13.a.

${ }^{23}$ Comissão Europeia. Relatório de 2011 sobre a aplicação da Carta Europeia de Direitos Fundamentais. Luxemburgo: Serviço de Publicações da União Europeia, 2012. p. 63.

Disponível em:<http://www.igfse.pt/upload/docs/2013/Reldireitosfundamentais2011.pdf $>$. Acesso em: 06 maio 2014. 
No mesmo sentido a Carta Europeia de Direitos Fundamentais assegura aos nacionais dos Estados-Membros da União o direito a existência de condições justas de trabalho, assim como o direito dos cidadãos a "prestações de segurança social e a serviços sociais, que prevejam proteção em caso de maternidade, doença, acidentes de trabalho, dependência ou velhice”.

Progressivamente, como visto no item anterior do presente artigo, o Tribunal de Justiça da União Europeia passa a examinar questões, a título de Reenvio Prejudicial e que envolvem a Carta Europeia de Direitos Fundamentais. Em muitos dos casos a aplicação da Carta Europeia de Direitos Fundamentais é invocada na própria jurisdição estatal na qual supostamente teria ocorrido a violação ao direito comunitário.

Como mencionado anteriormente, o Reenvio Prejudicial é utilizado nas hipóteses em que o juiz nacional deve analisar uma questão dentro de sua própria jurisdição e que envolva o Direito da União Europeia. Ao surgir alguma dúvida, no sentido de se saber como interpretar e aplicar a norma da União Europeia, o juiz nacional poderá suscitá-la ao juiz supranacional, de forma a garantir a uniformidade na interpretação e aplicação do Direito Comunitário.

Ainda que o tema, referente aos Direitos Fundamentais, seja novidade dentro do Tribunal de Justiça da União Europeia, progressivamente começam a aparecer questões que envolvem a Carta Europeia de Direitos Fundamentais, cujos dispositivos passam a ser invocados dentro das jurisdições nacionais como na supranacional, de forma a permitir o verdadeiro diálogo entre jurisdições.

Neste sentido vale citar como exemplo o Acórdão decorrente dos Processos C-297/10 e C-298/10 (Reenvio Prejudicial) interpostos por Sabine Hennigs contra Eisenbahn-Budesamt e Land Berlin contra Alexander Mai, julgado em data de 08 de

Comissão Europeia. Relatório de 2011 sobre a aplicação da Carta Europeia de Direitos Fundamentais. Luxemburgo: Serviço de Publicações da União Europeia, 2012. p. 67.

Disponível em: <http://www.igfse.pt/upload/docs/2013/Reldireitosfundamentais2011.pdf>. Acesso em: 06 maio 2014. 
setembro do ano de 2011 pelo Tribunal de Justiça da União Europeia ${ }^{24}$.

Especificamente a questão versou sobre a interpretação da Diretiva 2000/78/CE (artigos $2^{\circ}$, parágrafos $2^{\circ}$ e $6^{\circ}$ ) e a Carta Europeia de Direitos Fundamentais, artigos 21 e 28; em relação à proibição da adoção de políticas discriminatórias aos trabalhadores em decorrência da idade, notadamente porque a Diretiva em questão proíbe qualquer discriminação em decorrência da idade, o que é reafirmado pela Carta Europeia de Direitos Fundamentais.

Assim decidiu a Tribuna de Justiça da União Europeia ${ }^{25}$ :

Pedido de decis ão prejudicial - Bundesarbeitsgericht - Interpreta ção do artigo $21^{\circ}$ da Carta dos Direitos Fundamentais da União Europeia (JO C 83, de 30 de Março de 2010, p. 389), tal como concretizada na Directiva 2000/78/CE do Conselho, de 27 de Novembro de 2000, que estabelece um quadro geral de igualdade de tratamento no emprego e na actividade profissional (JO L 303, p. 16) - Remuneração dos agentes contratuais na função pública de um Estado-Membro - Regime nacional que prevê um vencimento de base diferente em função da idade.

Dispositivo

O princ f́pio da não discrimina ção em razão da idade consagrado no artigo $21^{\circ}$ da Carta dos Direitos Fundamentais da União Europeia e concretizado pela Directiva 2000/78/CE do Conselho, de 27 de Novembro de 2000, que estabelece um quadro geral de igualdade de tratamento no emprego $e$ na actividade profissional $e$, mais particularmente, os artigos $2^{\circ}$ e $6^{\circ}, n .1$, dessa directiva devem ser interpretados no sentido de que se op õem a uma medida prevista por uma conven ção colectiva, como a que está em causa no processo principal, que prevê que, dentro de cada grau, o escalão de remunera ção de base de um agente contratual do sector público seja determinado, na altura do recrutamento desse agente, em fun ção da sua idade. A esse propósito, o facto de o direito da União se opor à referida medida e de esta figurar numa convenção colectiva não prejudica o direito de negociar e de celebrar convençôes colectivas reconhecido no artigo $28^{\circ}$ da Carta dos Direitos Fundamentais da União Europeia.

Os artigos $2^{\circ}$ e 6o, $n$. 1, da Directiva 2000/78, bem como o artigo 28ㅇ da Carta dos Direitos Fundamentais da União Europeia, devem ser interpretados no sentido de que não se opõem a uma medida prevista por uma conven ção colectiva, como a que está em causa no processo principal, que substitui um regime de remuneração que cria uma discrimina ção em razão da idade por um regime de remunera ção baseado em critérios objectivos, mantendo, no entanto, por um per 1́do transitório e limitado no tempo, alguns dos efeitos discriminatórios do primeiro desses regimes, a fim de assegurar aos agentes em funções a transição para o novo regime sem terem de sofrer uma perda de

<http://curia.europa.eu/juris/document/document.jsf;jsessionid=9ea7d2dc30db756d54d815fc4ffeb1d0dc55 e76b2e42.e34KaxiLc3qMb40Rch0SaxuNb3b0?text=\&docid=109244\&pageIndex=0\&doclang=ES\&mode= lst\&dir=\&occ=first\&part=1\&cid=303932>. Acesso em: 07 maio 2014. 


\section{rendimentos.}

Concretamente, no caso específico, a Diretiva 2000/78, em seu artigo 18 estabelecia que os Estados-Membros da União Europeia poderiam dispor de um prazo adicional de três anos para a internalização da Diretiva. De fato, no caso da Alemanha o prazo para a incorporação da Diretiva venceu em 2 de dezembro do ano de 2003. Assim a presente Diretiva deveria produzir efeitos dentro da Alemanha até o dia 02 de dezembro de $2006^{26}$.

A Lei Geral alemã referente à igualdade de tratamento, por sua vez, estabelece que é admissível a existência de um tratamento diferenciado em decorrência de idade ou outras questões objetivas que justifiquem referida questão ${ }^{27}$.

Consequentemente, como a Diretiva se traduz em uma normativa da União Europeia que é aplicada para as matérias de competência partilhada, poderá o Estado legislar concorrentemente, como se verificou no caso em questão.

A atuação do Tribunal de Justiça da União Europeia, através do Reenvio Prejudicial demonstra a própria evolução do Direito da União Europeia e a constante atuação do Tribunal de Justiça supranacional, no sentido de - efetivamente - velar pela correta aplicação e interpretação do Direito Comunitário.

Com a incorporação da Carta Europeia de Direitos Fundamentais ao acervo jurídico comunitário, como visto anteriormente, haverá um aumento de questões relacionadas com o Direito da União Europeia e que envolvam os direitos fundamentais, quer seja em relação às jurisdições nacionais ou mesmo na jurisdição supranacional.

Portanto, inegável reconhecer o próprio avanço do Direito da União

26

Disponível

em: <http://curia.europa.eu/juris/document/document.jsf;jsessionid=9ea7d2dc30db756d54d815fc4ffeb1d0dc55 e76b2e42.e34KaxiLc3qMb40Rch0SaxuNb3b0?text=\&docid=109244\&pageIndex=0\&doclang=ES\&mode= lst\&dir=\&occ=first\&part=1\&cid=303932>. Acesso em: 07 maio 2014.

27 Disponível em: <http://curia.europa.eu/juris/document/document.jsf;jsessionid=9ea7d2dc30db756d54d815fc4ffeb1d0dc55 e76b2e42.e34KaxiLc3qMb40Rch0SaxuNb3b0?text=\&docid=109244\&pageIndex=0\&doclang=ES\&mode= lst\&dir=\&occ=first\&part=1\&cid=303932> . Acesso em: 07 maio 2014. 
Europeia, no sentido de se buscar a interpretação e aplicação uniforme do direito supranacional, de forma a contribuir para o aperfeiçoamento dos mecanismos de proteção aos direitos fundamentais dentro do bloco econômico.

\section{CONSIDERAÇÕES FINAIS}

A incorporação da Carta Europeia dos Direitos Fundamentais dentro do acervo jurídico comunitário representa um grande avanço dentro do bloco econômico, no que diz respeito à inclusão de novos valores dentro das políticas integracionistas as quais agora - mais do que nunca - passam a observar os valores voltados para a proteção da pessoa humana. Neste sentido, logicamente, torna-se mais do que necessário à existência de efetivos mecanismos de controles jurisdicionais, com o intuito de observar a proteção dos direitos fundamentais dentro da União Europeia.

Se por um lado o Tratado de Lisboa de 2009, garante a obrigatoriedade no cumprimento dos direitos fundamentais previstos na Carta Europeia, não há como se negar que o seu âmbito de atuação resume-se aos temas voltados para as competências da União Europeia (aquelas matérias referentes ao mercado comum) e, assim, tanto as instituições supranacionais como os Estados ficam limitados na aplicação de suas políticas, aos direitos estabelecidos naquele instrumento.

Por outro lado, o que se verifica é um maior respeito aos direitos dos cidadãos da União Europeia, no sentido de se buscar uma autoafirmação no próprio conceito de cidadania comunitária e a possibilidade de se buscar a tutela dos direitos ali dispostos, tanto dentro das jurisdições nacionais, como na supranacional.

Dentro do modelo supranacional, construído dentro da União Europeia, que estabelece uma clara divisão de competências entre as instituições do bloco econômico e as jurisdições nacionais, a atuação do Tribunal de Justiça da União Europeia é extremamente importante. Referida atuação, no tocante aos mecanismos de proteção aos direitos fundamentais se traduz na ação processual do Reenvio Prejudicial, que garante um 
constante diálogo entre a jurisdição supranacional e as jurisdições nacionais, de forma a garantir a uniformidade na interpretação e na aplicação do Direito da União Europeia.

O Direito da União Europeia, que ao longo dos anos vem construindo um engenhoso e criativo mecanismo dentro do bloco econômico, traduzido no chamado direito derivado comunitário, e que se iniciou com políticas meramente econômicas e comerciais, com o Tratado de Maastrich avançou no sentido de criar a cidadania europeia e, agora, inquestionavelmente inaugura-se uma nova fase mediante uma atuação - cada vez mais efetiva - tanto por parte dos tribunais nacionais como do Tribunal de Justiça da União Europeia, no que diz respeito à defesa dos Direitos Fundamentais dentro do bloco.

\section{REFERÊNCIAS}

BALAGUER CALLEJÓN, Francisco. As relações entre o Tribunal de Justiça da União Europeia e os Tribunais Constitucionais dos Estados-Membros, publicado na Revista Brasileira de Direitos Fundamentais e Justiça n.13, PUCRS, out/dez 2010;

CHÂTELET, François e PISIER-KOUCHENER Évelyne. As Concepções Políticas do Século XX - História do Pensamento Político, Zahar:RJ,1983;

CRETELLA NETO, José. Curso de Direito Internacional Econômico, ed. Saraiva: SP, 2012;

GOMES, Eduardo Biacchi. Manual de Direito da Integração Regional, 2a .ed., Juruá:2014;

JÚNIOR, Marcos Augusto de Albuquerque Ehrhardt; TORRES, Marcio Roberto. Direitos Fundamentais e as Relações Privadas: Superando a (Pseudo) Tensão entre Aplicabilidade Direta e Eficácia Indireta para Além do Patrimônio. Revista Juridica, [S.1.], v. 53, n. 4, p. 326 - 356, fev. 2020. ISSN 2316-753X. Disponível em: <http://revista.unicuritiba.edu.br/index.php/RevJur/article/view/3222/371371738>.

Acesso em: 19 abr. 2020. doi:http://dx.doi.org/10.21902/revistajur.2316753X.v53i4.3222. 
KENNA, George Frost. O Declínio da Ordem Europeia de Bismarck, UNB:Brasília, 1985;

MELLO, Celso Duviver de Albuquerque. Curso de Direito Internacional Público, ed. Renovar, 2001

<http://europa.eu/legislation_summaries/justice_freedom_security/combating_discrimina tion/133501_pt.htm>. Acesso em: 04 maio 2014.

<http://www.igfse.pt/upload/docs/2013/Reldireitosfundamentais2011.pdf >. Acesso em: 04 maio 2014.

Comissão Europeia. Relatório de 2011 sobre a aplicação da Carta Europeia de Direitos Fundamentais. Luxemburgo: Serviço de Publicações da União Europeia, 2012. Disponível em: <http://www.igfse.pt/upload/docs/2013/Reldireitosfundamentais2011.pdf>. Acesso em: 06 maio 2014.

http://curia.europa.eu/juris/document/document.jsf;jsessionid=9ea7d2dc30db756d54d815 fc4ffeb1d0dc55e76b2e42.e34KaxiLc3qMb40Rch0SaxuNb3b0?text=\&docid=109244\&pa geIndex $=0 \&$ doclang $=E S \&$ mode $=1$ st $\&$ dir $=\&$ occ $=$ first $\&$ part $=1 \&$ cid $=303932>$. Acesso em: 07 maio 2014.

$<$ http://curia.europa.eu/juris/document/document.jsf?text=\&docid=113799\&pageIndex $=0$ $\&$ doclang $=$ PT $\&$ mode $=$ req $\&$ dir $=\&$ occ $=$ first $\&$ part $=1 \&$ cid $=330481>$. Acesso em: 07 maio 2014. 